\title{
Correction to: Translating Research to Policy: Setting Provider Payment Rates for Strategic Purchasing under India's National Publicly Financed Health Insurance Scheme
}

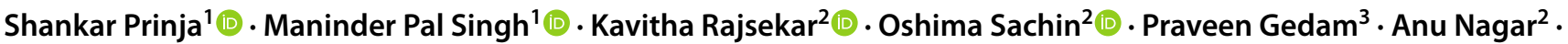 \\ Balram Bhargava ${ }^{2,4}$. CHSI Study Group $1,3,5,6,7,8,9,10,11,12,13,14$
}

Published online: 26 March 2021

(c) The Author(s), under exclusive licence to Springer Nature Switzerland AG part of Springer Nature 2021

\section{Correction to: Applied Health Economics and Health Policy https://doi.org/10.1007/s40258-020-00631-3}

The article note on the first page of the PDF that previously read:

"The members of the CHSI Study Group are mentioned in "Acknowledgments" section."

Should have read:

"CHSI Study Group: Jyotsna Naik ${ }^{1}$, Malkeet Singh ${ }^{1}$, Himanshi Tomar ${ }^{1}$, Rakesh Bahl ${ }^{5}$, Amit Sachdeva ${ }^{5}$, Sharminder Kaur ${ }^{5}$, Sanjay Kumar ${ }^{6}$, Setu Sinha ${ }^{6}$, Varsha Singh ${ }^{6}$, Avijit Hazra ${ }^{7}$, Raghunath Misra ${ }^{7}$, Divya Mehrotra ${ }^{8}, \mathrm{~K}$. Narayanasamy ${ }^{9}$, A. Chitra ${ }^{9}$, Arun Gupta ${ }^{3}$, Pankaj Bahuguna ${ }^{1}$, Kusum Lata Gaur ${ }^{10}$, Jai Prakash Pankaj ${ }^{10}$, Dharmesh Kumar Sharma ${ }^{10}$, Gajanan D. Velhal ${ }^{11}$, Amit S. Bhondve ${ }^{11}$, Prakash Patel ${ }^{12}$, Amit C. Patel ${ }^{12}$, Rajendra Joshi ${ }^{12}$, Kondeti Madhavi $^{13}$, Pulaganti Madhusudana ${ }^{13}$, Bhabagrahi Rath ${ }^{14}$, Sashi Bhusan Biswal ${ }^{14}$, Ankita Panigrahy ${ }^{14}$."

The original article can be found online at https://doi.org/10.1007/ s40258-020-00631-3.

Shankar Prinja

shankarprinja@gmail.com

1 Department of Community Medicine and School of Public Health, Postgraduate Institute of Medical Education and Research, Sector-12, Chandigarh 160012, India

2 Department of Health Research, Ministry of Health and Family Welfare, Government of India, New Delhi, India

3 National Health Authority, Ministry of Health and Family Welfare, Government of India, New Delhi, India

4 Indian Council of Medical Research, Ministry of Health and Family Welfare, Government of India, New Delhi, India

5 Government Medical College, Jammu, Jammu and Kashmir, India

6 Indira Gandhi Institute of Medical Science, Patna, Bihar, India
The original article has been corrected.

7 Institute of Postgraduate Medical Education \& Research, Kolkata, West Bengal, India

8 King George's Medical University, Uttar Pradesh, Lucknow, India

9 Madras Medical College, Chennai, Tamil Nadu, India

10 Sawai Man Singh Medical College, Jaipur, Rajasthan, India

11 Seth G S Medical College \& KEM Hospital, Mumbai, Maharashtra, India

12 Surat Municipal Institute of Medical Education \& Research, Surat, Gujarat, India

13 Multi-Disciplinary Unit, Sri Venkateswara Medical College, Tirupati, Andhra Pradesh, India

14 Veer Surendra Sai Institute of Medical Sciences and Research, Burla, Odisha, India 